\title{
Genetic and antigenic dynamics of influenza A viruses of swine on pig farms in Thailand
}

\author{
Junki Mine ${ }^{1,2} \cdot$ Haruka Abe $^{1,2} \cdot$ Sujira Parchariyanon ${ }^{3} \cdot$ Prakit Boonpornprasert $^{3} \cdot$ Namfon Ubonyaem $^{3}$. \\ Bandit Nuansrichay ${ }^{3} \cdot$ Nobuhiro Takemae $^{1,2} \cdot$ Taichiro Tanikawa $^{1,2} \cdot$ Ryota Tsunekuni $^{1,2} \cdot$ Yuko Uchida $^{1,2}$. \\ Takehiko Saito ${ }^{1,2}$
}

Received: 23 May 2018 / Accepted: 18 October 2018 / Published online: 10 November 2018

(c) Springer-Verlag GmbH Austria, part of Springer Nature 2018

\begin{abstract}
Surveillance studies of influenza A virus of swine (IAV-S) have accumulated information regarding IAVs-S circulating in Thailand, but how IAVs-S evolve within a farm remains unclear. In the present study, we isolated $82 \mathrm{~A}(\mathrm{H} 1 \mathrm{~N} 1)$ pdm09 and $87 \mathrm{H} 3 \mathrm{~N} 2$ viruses from four farms from 2011 through 2017. We then phylogenetically and antigenically analyzed the isolates to elucidate their evolution within each farm. Phylogenetic analysis demonstrated multiple introductions of A(H1N1)pdm09 viruses that resembled epidemic $\mathrm{A}(\mathrm{H} 1 \mathrm{~N} 1) \mathrm{pdm} 09$ strains in humans in Thailand, and they reassorted with $\mathrm{H} 3 \mathrm{~N} 2$ viruses as well as other $\mathrm{A}(\mathrm{H} 1 \mathrm{~N} 1) \mathrm{pdm} 09$ viruses. Antigenic analysis revealed that the viruses had acquired antigenic diversity either by accumulating substitutions in the hemagglutinin protein or through the introduction of IAV-S strains with different antigenicity. Our results, obtained through continuous longitudinal surveillance, revealed that IAV-S can be maintained on a pig farm over several years through the generation of antigenic diversity due to the accumulation of mutations, introduction of new strains, and reassortment events.
\end{abstract}

\section{Introduction}

Swine influenza is one of the most prevalent diseases in the global swine population. This disease is caused by influenza A virus of swine (IAV-S), which induces fever, dullness, loss of appetite, and respiratory symptoms. Typically, IAV-S causes only mild symptoms and low mortality rates, but coinfection of IAV-S and other pathogens results in a higher

Handling Editor: Hans Dieter Klenk.

Electronic supplementary material The online version of this article (https://doi.org/10.1007/s00705-018-4091-4) contains supplementary material, which is available to authorized users.

Takehiko Saito

taksaito@affrc.go.jp

1 Division of Transboundary Diseases, National Institute of Animal Health, National Agriculture and Food Research Organization (NARO), 3-1-5 Kannondai, Tsukuba, Ibaraki 305-0856, Japan

2 Thailand-Japan Zoonotic Diseases Collaboration Center, Kasetklang, Chatuchak, Bangkok 10900, Thailand

3 National Institute of Animal Health, Kasetklang, Chatuchak, Bangkok 10900, Thailand mortality rate and impairs average daily weight gain, resulting in tremendous economic losses to pig farmers worldwide [1-3]. Prior to 2009, IAV-S subtypes (H1N1, H1N2, and H3N2) predominated in swine throughout the world [4, 5]. Classical swine H1N1 IAV-S has been endemic in North America since the 1970s, whereas avian-like H1N1 IAV-S has maintained a stable presence since 1979 [6, 7]. In 1998, a triple-reassortant virus emerged through reassortment with a human seasonal virus, a classical swine IAV-S, and an avian influenza virus [8]. In April 2009, an IAV containing a combination of segments from both the triple-reassortant virus described above and a European swine lineage spread rapidly to cause a worldwide pandemic in humans [9, 10]. After the 2009 pandemic, pandemic A(H1N1)2009 [A(H1N1)pdm09] viruses were introduced into swine populations and reassorted with endemic IAVs-S, resulting in genetic diversity among IAV-S strains [11-17]. IAV-S typically circulates subclinically among pig populations [18] and is occasionally transmitted to turkeys in a subclinical form, causing economic losses in poultry production also [19, 20]. Therefore, IAV-S surveillance activities are urgently needed-not only to minimize economic loss to the livestock industry but also to monitor the emergence of novel IAV-S strains with pandemic potential $[21,22]$. 
Since the 1970s, the pig industry in Thailand has expanded rapidly to become a major livestock industry in the country; about 1,000,000 tons of pork were produced annually during the last decade [23]. In Thailand, IAV-S strains of the H1N1 and H3N2 subtypes were first isolated during the 1970s [24, 25]. After that, our studies and those of others revealed that IAV-S strains of the H1N1, H1N2, and H3N2 subtypes have circulated in Thailand [18, 26-29]. Since the 2009 pandemic, A(H1N1)pdm09 viruses have become dominant, replacing classical swine H1N1 viruses, and the internal genes of H3N2 IAV-S have been replaced by those of A(H1N1)pdm09 viruses [29-32]. These viruses were generated through coinfection of pigs followed by reassortment, as reported previously [33]. Several longitudinal surveillance studies have revealed the dynamics of IAV-S from introduction to extinction on swine farms [17, 34, 35]. However, how IAV-S might evolve to be retained within the pig population on a farm remains unclear.

In this study, we monitored five pig farms in Thailand from 2011 through 2017 to learn how IAV-S evolved within these populations. At the target farms, we collected nasal swabs from clinically healthy weaning pigs and sows for virus isolation followed by genetic and antigenic analysis. These analyses improve our understanding of how IAV-S strains evolve genetically and antigenically to be maintained longitudinally in a pig-farm setting.

\section{Materials and methods}

\section{Sample collection}

Using the same techniques that we used previously to isolate IAV-S from clinically healthy piglets (age, 3 to 10 weeks), which yielded an isolation rate of $4.2 \%$ in our previous study [18], we collected nasal swabs from clinically healthy weaning pigs and sows to investigate the dynamics of IAV-S on five pig farms (Table S1). Farms B and C are in Chonburi province, and farms $\mathrm{D}, \mathrm{O}$, and $\mathrm{P}$ are in Chachoengsao province; each of the farms had a different owner. Farms B and $\mathrm{C}$ adjoined each other, separated by a fence. Beginning in 2011, nasal swabs were collected 12 times (February and July 2011; July 2012; May, August, and November 2013; March 2014; July 2015; February and July 2016; and February and July 2017) at farms B and C; nine times (February, July, and October 2011; July 2012; February, August, and November 2013; March 2014; and July 2015) at farm D; five times (July 2015, February and July 2016, and February and July 2017) at farm O; and four times (February and July 2016 and February and July 2017) at farm P (Table S2). The number of swabs collected from weaning piglets and sows enabled the detection of at least one IAV-S-infected pig with a probability of 0.95 if the prevalence rate was higher than $15 \%$ in each population [36].

Nasal swabs were promptly placed in minimum essential medium containing penicillin (1000 units/ml), streptomycin $(1000 \mu \mathrm{g} / \mathrm{ml})$, amphotericin B $(25 \mu \mathrm{g} / \mathrm{ml})$, HEPES $(0.01 \mathrm{M})$, and $0.5 \%$ bovine serum albumin and were kept on ice packs until transported to the National Institute of Animal Health in Thailand. There, the swabs were removed, and the medium was aliquoted; several aliquots of each sample were stored at $-80{ }^{\circ} \mathrm{C}$ as stocks. The remaining samples were stored at $4{ }^{\circ} \mathrm{C}$ until used for virus detection within 24 hours and for virus isolation within 48 hours, as described later.

\section{Virus detection}

RNA was extracted from swab samples using RNeasy Mini Kits (QIAGEN, Hilden, Germany) as described previously $[18,30]$. The extracted RNA was reverse transcribed to cDNA using Superscript III (Invitrogen, Carlsbad, CA, USA) and universal primers for influenza A virus [37]. cDNA was used as the template for real-time PCR analysis using SYBR Premix Ex Taq (Takara Bio, Shiga, Japan) with primers specific for the matrix protein (MP) gene as described previously [38].

\section{Virus isolation}

For virus isolation, medium from nasal swab samples that were positive according to real-time PCR analysis were filtered (pore size, $0.45 \mu \mathrm{m}$; Millipore, Danvers, MA, USA) and inoculated into the allantoic cavities of 10-day-old embryonated chicken eggs and cultures of Madin-Darby canine kidney cells in minimum essential medium containing penicillin (100 units $/ \mathrm{ml})$, streptomycin $(100 \mu \mathrm{g} / \mathrm{ml})$, amphotericin B $(2.5 \mu \mathrm{g} / \mathrm{ml})$, gentamicin $(25 \mu \mathrm{g} / \mathrm{ml}), 3 \times$ Minimum Essential Medium Vitamin Solution (Invitrogen), $1 \times$ GlutaMAX (Invitrogen), $0.4 \%$ bovine serum albumin, and 0.5 to $3.0 \mu \mathrm{g}$ of trypsin per ml. After 4 days of incubation at $37{ }^{\circ} \mathrm{C}$ in the presence of $5 \% \mathrm{CO}_{2}$, the supernatants of these cell cultures were used in HA assays [39] with guinea pig erythrocytes.

\section{Genomic sequencing and phylogenetic analysis}

Each gene segment of isolated viruses was sequenced using Sanger or next-generation sequencing. Sanger sequencing was performed as described in previous reports [24, 29]; information regarding the PCR primers will be provided on request. The complete genome sequences of viruses isolated after July 2016 were obtained through next-generation sequencing (Miseq, Illumina, San Diego, CA, USA). cDNA libraries for next-generation sequencing were prepared using 
an NEBNext Ultra RNA Library Prep Kit for Illumina (New England Biolabs, Ipswich, MA, USA) and sequenced using a Miseq Reagent Kit version 2 (Illumina). Consensus sequences were generated using FLUGAS software (version 1.0.0, World Fusion, Tokyo, Japan). The nucleotide sequences and isolation information for the viruses analyzed have been deposited in the GISAID EpiFlu database (http:// www.gisaid.org); isolate ID numbers are listed in Table S3.

For phylogenetic analysis, we downloaded complete sequences of each genome (basic polymerase [PB] 2, 46,130 nucleotides (nt); PB1, 34,052 nt; acidic polymerase [PA], 48,692 nt; H1 HA, 35,983 nt; H3 HA, 32,481 nt; nucleoprotein [NP], 46,441 nt; $\mathrm{N} 1$ neuraminidase [NA], 34,502 nt; N2 NA, 34,264 nt; MP, 61,853 nt; and nonstructural protein [NS], 48,857 nt) from the GISAID databases (http://platf orm.gisaid.org/epi3/frontend) in January 2017. Sequences of the isolates obtained during this study and all downloaded sequences were aligned using BioEdit [40] and MAFFT [41]. After alignment, sequences with ambiguous nucleotide bases were removed; the remaining sequences were used for phylogenetic analysis in MEGA-CC with 100 bootstrap replicates, using the maximum-likelihood method with the general time-reversible model [42].

In addition, we constructed maximum clade credibility (MCC) trees to calculate molecular estimates of substitution rates and divergence times for the viruses. MCC trees were constructed using the Bayesian Evolutionary Analysis by Sampling Tree (BEAST) method [43]. Alignments of each gene were formatted using the Bayesian Evolutionary Analysis Utility at the default settings, except for clock rate; the initial clock rate was set as $1.0 \times 10^{-5}$ to fit the substitution rate of influenza viruses for constructing trees. Calculation was set as $1 \times 10^{8}$ to $1 \times 10^{9}$ steps in length, where the number of steps was that needed to obtain an effective sample size of more than 200. Substitution rates and $\mathrm{Ka} / \mathrm{Ks}$ ratios of genes were calculated as described earlier and were expressed using the Tracer function of BEAST [44].

\section{Antigenic analysis}

Hemagglutination inhibition (HI) tests were performed using $0.5 \%$ ( $\mathrm{vol} / \mathrm{vol}$ ) guinea pig erythrocytes according to the standard method [39]. Post-infection ferret sera against the human H3N2 viruses A/Wuhan/359/95 (Wuh95), A/ Sydney/5/97 (Syd97), A/Panama/2007/99 (Pan99), A/ Wyoming/3/2003 (Wyo03), A/New York/55/2004 (NY04), A/Hiroshima/52/2005 (Hir05), and A/Uruguay/716/2007 (Uru07); hyperimmune chicken sera against the swine H3N2 viruses A/swine/Chachoengsao/2003 (Cha03) and A/swine/Saraburi/107725-28/2008 (Sar08); and hyperimmune chicken sera against the H1N1 viruses A/swine/ Narita/aq21/2011 (Nar11) and California/04/2009 (Cal09) were used for antigenic analysis. Swine sera collected at farm C during May and December 2014 and July 2015 were used in HI tests against viruses isolated in this study. To remove nonspecific inhibitors of hemagglutination, all sera and antisera were treated with receptor-destroying enzyme from Vibrio cholerae (Denka Seiken, Tokyo, Japan) according to the manufacturer's protocol. Subsequently, each mixture was adsorbed to packed guinea pig erythrocytes for 60 $\min$ at room temperature.

\section{Results}

\section{Sample collection and virus isolation}

In total, the 3790 swabs collected from the five farms in this study yielded 169 IAV-S isolates comprising $82 \mathrm{H} 1 \mathrm{~N} 1$ isolates and $87 \mathrm{H} 3 \mathrm{~N} 2$ isolates during the monitoring period (2011 through 2017). No influenza virus isolates were obtained from farm $\mathrm{P}$, giving an overall IAV-S isolation rate of $4.5 \%$ (Tables 2 and $\mathrm{S} 4$ ).

From farm B in Chonburi province, we isolated $36 \mathrm{H} 1 \mathrm{~N} 1$ and $34 \mathrm{H} 3 \mathrm{~N} 2$ viruses (isolation rate, 6.7\%). Two H3N2 (H3 ChoB11.2) viruses were isolated in February 2011, and two H1N1 viruses (H1_ChoB12.7) were isolated in July 2012. After the first isolation of these two subtypes, we isolated H1N1 viruses in May 2013 (H1_ChoB13.5), July 2015, July 2016, and February 2017; H3N2 viruses were isolated in May 2013, August 2013, and March 2014 (Tables 2 and S4).

From farm $\mathrm{C}$ in Chonburi province, we isolated two $\mathrm{H} 1 \mathrm{~N} 1$ and three $\mathrm{H} 3 \mathrm{~N} 2$ viruses (isolation rate, $0.5 \%$ ). No virus was isolated until July 2015, when samples yielded two H3N2 (H3_Cho15.7) isolates. After July 2015, two H1N1 (H1_ChoC16.2) and one H3N2 (H3_ChoC17.2) viruses were isolated in February 2016 and February 2017, respectively.

From farm D in Chachoengsao province, we isolated 45 $\mathrm{H} 1 \mathrm{~N} 1$ and five $\mathrm{H} 3 \mathrm{~N} 2$ viruses (isolation rate, 6.4\%). These viruses comprised H1N1 viruses isolated in February 2011, October 2011, July 2012, February 2013, August 2013, November 2013, and March 2014 and H3N2 viruses isolated in July 2012, February 2013, and July 2015 (Tables 2 and S4).

From farm $\mathrm{O}$ in Chachoengsao province, where we started monitoring in July 2015, we isolated 44 H3N2 viruses (isolation rate, $10.9 \%$ ). We isolated $18 \mathrm{H} 3 \mathrm{~N} 2$ viruses (H3_ChaO16.7) in July 2015, followed by another 26 H3N2 viruses (H3_ChaO17.7) in July 2017.

\section{Genetic evolution of IAVs on the tested pig farms}

To investigate the genetic evolution of the IAV-S isolates obtained in the current study, we determined the entire genome sequence of each isolate and performed 
phylogenetic analysis of each segment. The HA gene of the Thai H1N1 viruses isolated in this study originated from $\mathrm{A}(\mathrm{H} 1 \mathrm{~N} 1) \mathrm{pdm} 09$ viruses, classified as $1 \mathrm{~A}$ classical swine lineage 3.3.2 [45], and these formed three distinct clusters with bootstrap values of more than $60 \%$, designated respectively as 3.3.2a, 3.3.2b, and 3.3.2c in the current study (Fig. S1).
The HA genes belonging to 3.3.2a consisted of the H1N1 viruses from farms B and C from 2012 through 2017 (Fig. 1a). Those genes originated from A(H1N1)pdm09 viruses isolated from humans and swine in Asia (including Thailand) in 2009, and shared a putative common ancestor with A/swine/Saraburi/NIAH116627-24/2009 and A/

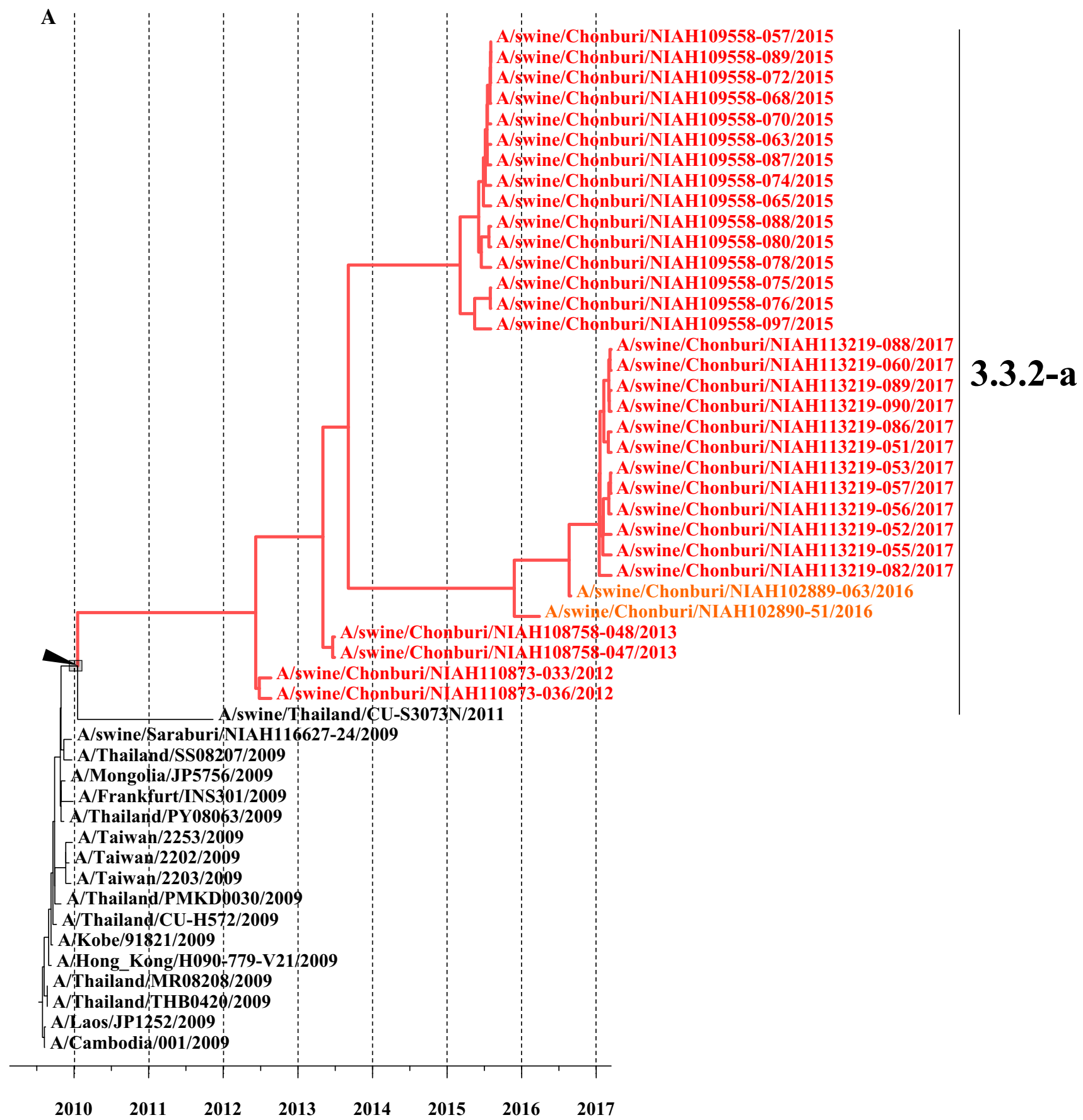

Fig. 1 Detail trees derived from an H1 HA maximum clade credibility (MCC) phylogenetic tree based on the genes of viruses isolated in this study and downloaded from the GISAID databases. Genetic groups 3.3.2a, 3.3.2b, and 3.3.2c are shown in lines colored with light red (a), pink (b), and blue (c), respectively, in each panel. Strain names of isolates from farms B, C, and D are shown in red, orange, and blue, respectively. The gray box in each tree indicates the divergence time estimated using BEAST 


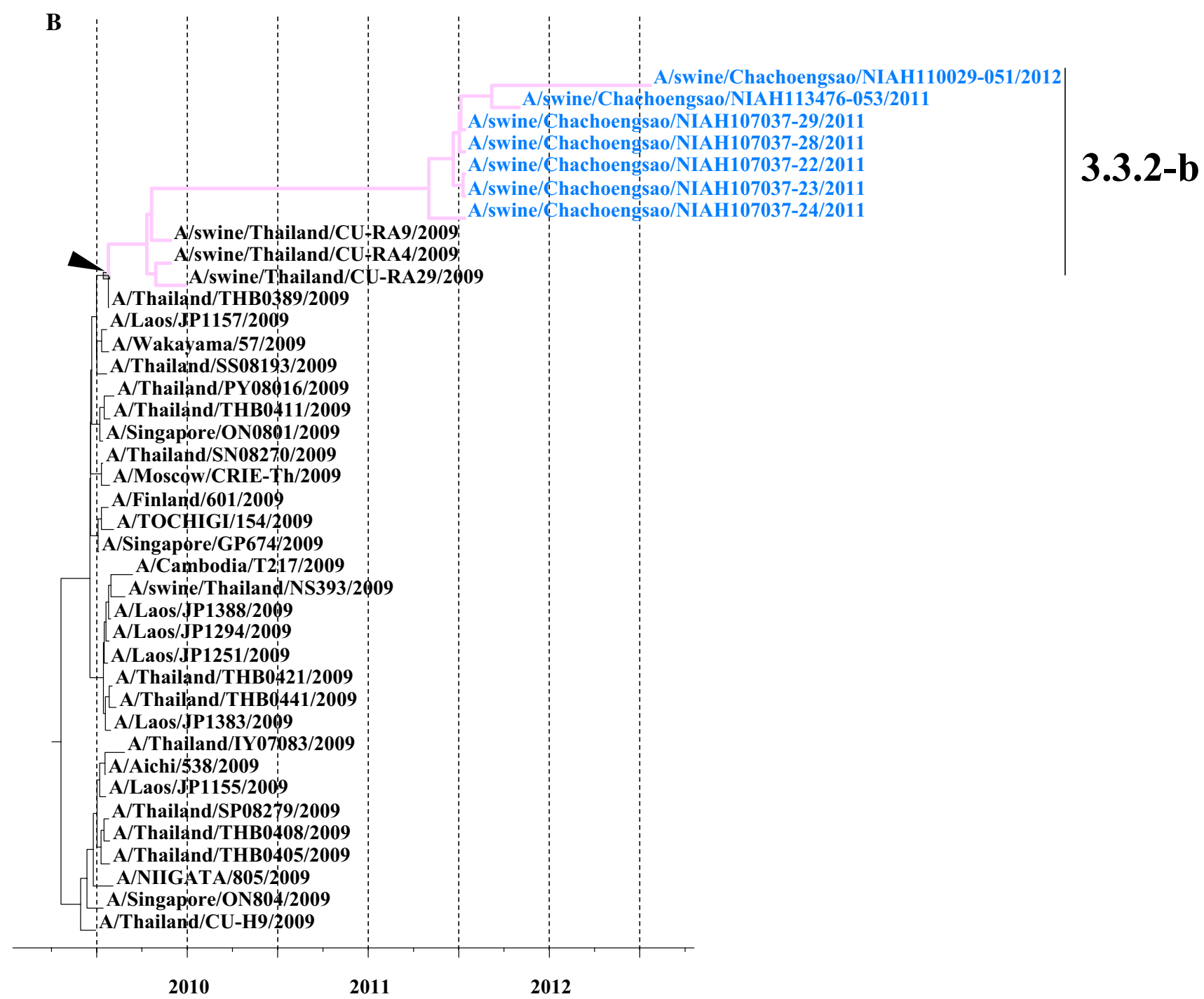

Fig. 1 (continued)

Thailand/SS08208/2009 (Fig. 1A). 3.3.2a genes were estimated to diverge as a phylogenetic group on 17 January 2010 (95\% highest posterior density value [HPDV], 20 October 2009 to 22 April 2010; black arrow, Fig. 1a).

Clusters 3.3.2b and -c of the H1 HA genes consisted of the viruses obtained in 2011 and 2012 and in 2013 and 2014, respectively, from farm D (Fig. $1 \mathrm{~b}$ and c). The HA genes of 3.3.2b originated from $\mathrm{A}(\mathrm{H} 1 \mathrm{~N} 1) \mathrm{pdm} 09$ viruses isolated from humans and swine in Asia in 2009, and a group of Thai IAV-S isolates including A/swine/Thailand/CU-RA9/2009 formed an out-group of this cluster. The HA genes of 3.3.2b were estimated to diverge from human isolates on 25 July 2009 (95\% HPDV, 12 July 2009 to 25 July 2009; black arrow in Fig. 1b). In contrast, genes of 3.3.2c originated from human viruses in 2010 to 2011 , and a putative ancestral strain of 3.3.2c was estimated to diverge from those viruses on 25 January 2011 (95\% HPDV, 18 October 2010 to 4 April 2011; black arrow, Fig. 1c).

The H3N2 viruses isolated in this study had the HA genes of the human-like IAV-S strains circulating among swine populations in Thailand (Fig. S2). They were divided into two distinguishable clades with bootstrap values of $98 \%$, designated as human-like a and human-like b. The human-like a clade consisted of the viruses isolated from farms $\mathrm{B}$ and $\mathrm{D}$, and the human-like $\mathrm{b}$ viruses were those from farms $\mathrm{C}$ and $\mathrm{O}$ (Fig. 2). Both human-like a and human-like $\mathrm{b}$ originated from a seasonal influenza virus during 1996-1998, and they diverged as human-like a and human-like b in the late 1990s (95\% HPDV, 1 January 1997 to 4 February 2001; black arrow, Fig. 2). No previous Thai IAV-S isolate belonging to the human-like a cluster has been recognized, whereas IAV-S isolates belonging 


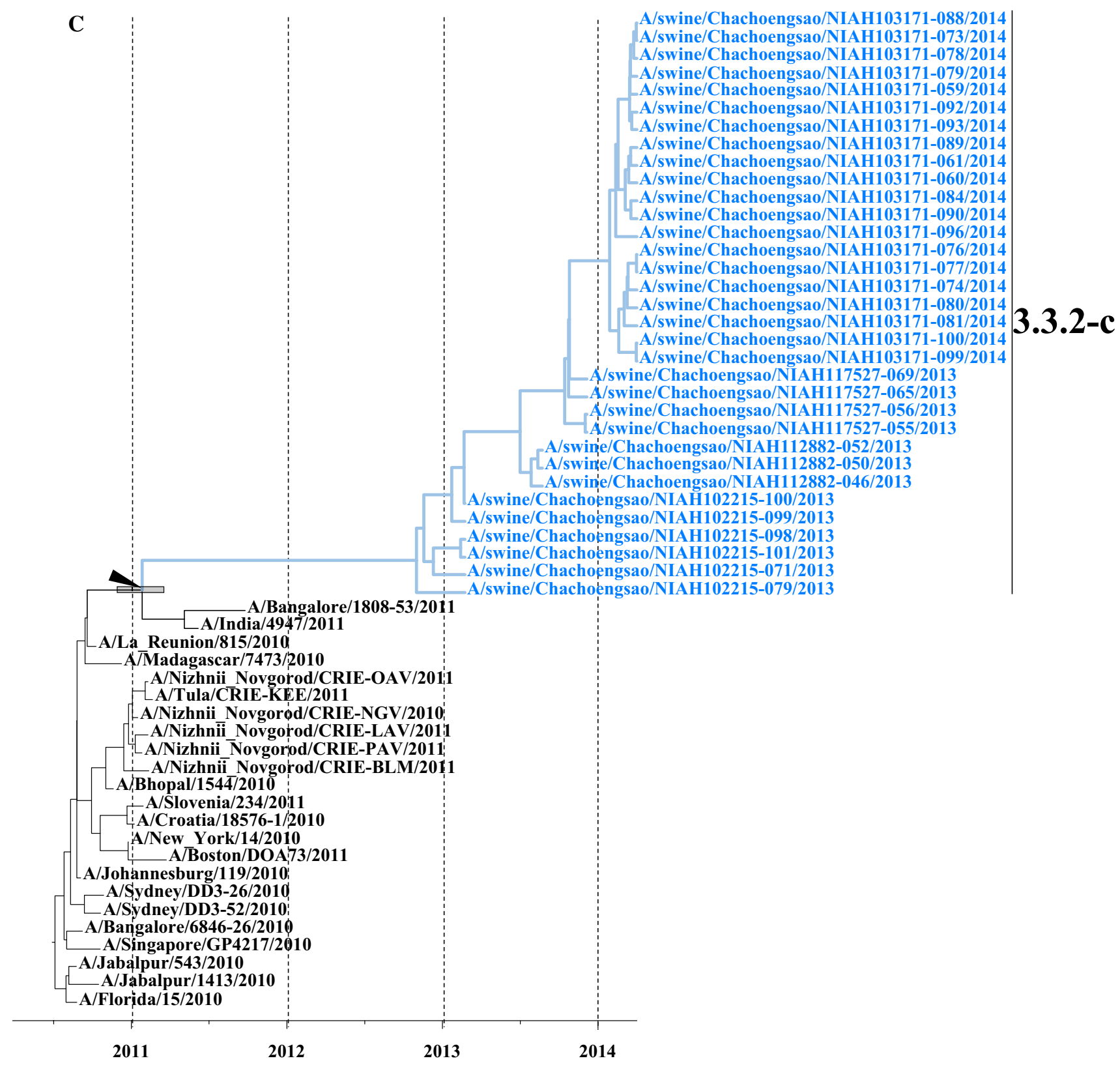

Fig. 1 (continued)

to the human-like b cluster in this study were related to Thai H3N2 IAV-S isolates from 2005 to 2014, and they diverged around 2011 (95\% HPDV, 8 November 2010 to 21 November 2011; red arrow, Fig. 2) from the human-like b Thai IAV-S strains.

The N2 genes of H3N2 viruses isolated from four of the five farms in this study originated from a seasonal influenza virus in the mid-1990s (Fig. S3A), and their patterns of divergence were similar to that of human-like a $\mathrm{H} 3$ genes, as described earlier (Fig. S3b). Both surface genes were retained within Thai pig populations for approximately 20 years after the introduction of the human virus, suggesting these genes gradually evolved to be endemic in pig populations.

The internal genes of the viruses isolated in this study originated from $\mathrm{A}(\mathrm{H} 1 \mathrm{~N} 1) \mathrm{pdm} 09$ viruses and were divided into groups 3.3.2a, $-\mathrm{b}$, and $-\mathrm{c}$, as they were for the $\mathrm{H} 1$ genes. This pattern typically was seen for the PB1 genes (Fig. S4a). 3.3.2a originated from A(H1N1)pdm09 viruses isolated from humans and swine in Asia (Fig. S4b). 3.3.2b originated from another group of $\mathrm{A}(\mathrm{H} 1 \mathrm{~N} 1)$ pdm09 viruses isolated from humans and swine in Asia (Fig. S4c). 3.3.2c originated from a group of $\mathrm{A}(\mathrm{H} 1 \mathrm{~N} 1)$ pdm09 viruses isolated from humans and swine from various areas during 
2010 to 2011 (Fig. S4d). In addition, 3.3.2c formed a further outgroup, designed as 3.3.2 $\mathrm{c}^{\prime}$ (Fig. S4e). Like 3.3.2c, 3.3.2 $\mathrm{c}^{\prime}$ originated from $\mathrm{A}(\mathrm{H} 1 \mathrm{~N} 1) \mathrm{pdm} 09$ viruses isolated from humans in Thailand in 2010 (Fig. S4d, red arrow). The MP genes of viruses isolated from farm B in July 2015 and the NP genes of viruses isolated from farm $\mathrm{O}$ were classified as 3.3.2c, even though they were not identified as an additional subclade (Figures S5, S6a and b). The topology of the N1 NA, PB2, and PA genes of the Thai IAV-S isolates in this study were similar to those of the H1 HA and PB1 genes. However, the sequences of the NP, MP, and NS genes of the viruses were so closely related between 3.3.2a and - $b$ that they were not phylogenetically distinguishable (bootstrap value, $<60 \%$ ), and they were therefore designated as 3.3.2ab (Fig. S6a and c).

Because the divergence pattern was similar between the H1 HA and PB1 genes, as described, we compared their estimated divergence times (Table 1). Whereas the time of divergence differed by only 1 month between the H1 HA and PB1 genes in 3.3.2a, the dates of divergence for 3.3.2b and 3.3.2c of PB 1 genes were at least 4 and 6 months earlier than those of H1 HA genes. However, such deviations might reflect differences of the numbers of full-length genes registered in the database.

Next, we scrutinized the genetic constellation of the viruses on each farm based on the genetic designation we described earlier (Table 2). On farm B, except for two cases, the constellation of $\mathrm{H} 1 \mathrm{~N} 1$ viruses remained the same throughout the monitoring period-the viruses in the constellation carried the HA, NA, PB2, PB1, and PA genes of 3.3.2a and the NP, MP, and NS genes of 3.3.2ab until July 2017. The two exceptional cases arose in July 2015, when the isolates at that time had the PB2 of 3.3.2b or MP of 3.3.2c. These data suggest that, before July 2015, new viruses carrying the PB2 gene originated from humans in 2009 and/or the MP gene that originated in 2010 to 2011 was introduced into farm B, where these viruses reassorted with those that had circulated but had not been established on the farm. Although the first isolated viruses from farm B were H3N2 viruses in February 2011, the constellations of the internal genes described earlier were shared by both $\mathrm{H} 1 \mathrm{~N} 1$ and $\mathrm{H} 3 \mathrm{~N} 2$ viruses, suggesting that $\mathrm{H} 1 \mathrm{~N} 1$ viruses carrying the original gene constellations might have been circulating on farm B before February 2011.

On farm C, the gene constellations of the H1N1 viruses, H1_ChoC16.2, were the same as for the exceptional H1N1 viruses isolated on farm B in July 2015, H1_ChoB15.7B. Although the origin of the $\mathrm{H} 3 \mathrm{HA}$ genes on farm $\mathrm{C}$ differed from that of farm B, that of the internal and NA genes of the H3N2 viruses, H3_ChoC15.7 and H3_ChoC17.2, were the same as that of those isolated on farm B (Table 2). $\mathrm{H} 3 \mathrm{~N} 2$ viruses with the same gene constellations were retained on farm C for at least 1.5 years (July 2015 through February 2017).

On farm D, H1N1 viruses that had the same gene constellation as H1_ChoD11.2 persisted until July 2012. Then, in February 2013, other H1N1 viruses emerged, of which all of the gene segments originated from 3.3.2c A(H1N1)pdm09 viruses, thus indicating another introduction of $\mathrm{A}(\mathrm{H} 1 \mathrm{~N} 1)$ pdm09 viruses into farm D. H3N2 viruses isolated after July 2012 carried the same internal genes as H1N1 viruses that circulated after February 2013. However, the origin of the internal genes of H3_ChaD12.7 and H3_ChaD13.2 differed from that of H3_ChaD15.7, as illustrated by the PB1 phylogeny (Fig. S4d). Like the situation on farm B, although the first viruses carrying genes of $3.3 .2 \mathrm{c}$ on farm D were $\mathrm{H} 3 \mathrm{~N} 2$ viruses in July 2012, H1N1 viruses carrying all genes of 3.3.2 c might have been circulating before July 2012, reassorting with the H3N2 strains to yield H3_ChoD12.7.

On farm $\mathrm{O}, \mathrm{H} 3 \mathrm{~N} 2$ viruses with the same gene constellation had persisted for at least one year (July 2016 to July 2017).

\section{Antigenic analysis of the Thai isolates}

We performed HI assays to ascertain whether antigenic differences were present among the IAVs-S isolated in the current study. All viruses isolated in this study reacted with hyperimmune chicken sera raised against Cal09, with HI titers less than 2-fold lower than that of the homologous virus. In contrast, viruses isolated on farms B and D showed 4-fold differences in reactivity with the other two hyperimmune chicken sera. Among the A(H1N1)pdm09 viruses isolated from pigs on farm $\mathrm{B}$, whose $\mathrm{H} 1 \mathrm{HA}$ genes phylogenetically belonged to 3.3.2a, H1_ChoB 12.7 showed higher reactivity with hyperimmune chicken sera raised against Nar11 and H1_ChoC16.2, whereas H1_ChoB17.2 showed a 4-fold lower titer, suggesting gradual antigenic drift among the $\mathrm{A}(\mathrm{H} 1 \mathrm{~N} 1) \mathrm{pdm} 09$ viruses isolated from farm $\mathrm{B}$ (Table 3). Among the $\mathrm{A}(\mathrm{H} 1 \mathrm{~N} 1) \mathrm{pdm} 09$ viruses isolated from pigs on farm D, H1_ChaD11.2, H1_ChaD11.10, and H1_ChaD12.7, whose H1 HA genes belonged to 3.3.2b, reacted with hyperimmune chicken sera raised against $\mathrm{H} 1$ ChoC16.2, with titers of 160 or 320, whereas H1_ChaD13.2, H1_ChaD13.8, H1_ChaD13.11, all of which carried H1 HA genes of 3.3.2c, reacted with a titer of 640 . In addition, the latest H1_ChaD14.3 that had H1 HA genes of 3.3.2c showed 4-fold lower reactivity than H1_ChaD13.2, H1_ChaD13.8, and H1_ChaD13.11 viruses.

Antigenic changes were present among $\mathrm{H} 3$ isolates obtained from the same farm as well as among those obtained from different farms. The reactivity of H3 ChoB11.2 with anti-Sar08 hyperimmune chicken sera was clearly distinguishable from those of H3_ChoB13.5, H3 ChoB13.8, and H3_ChoB14.3. H3_ChoB11.2 reacted with 


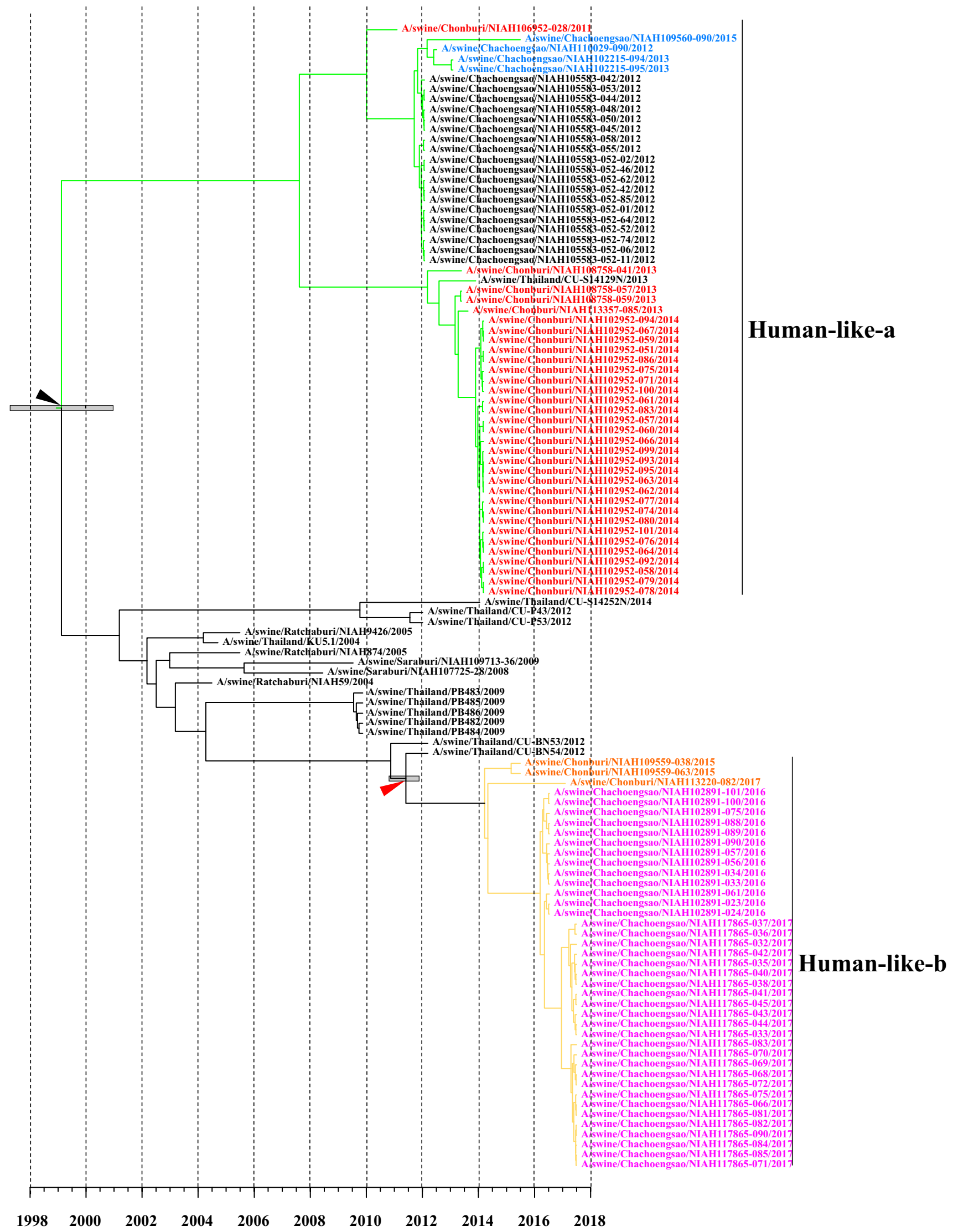


4Fig. 2 Detail trees derived from an H3 HA MCC phylogenetic tree based on genes of viruses isolated in this study and downloaded from the GISAID databases. The genetic group human-like a is shown in lines colored with green, and human-like $b$ is in yellow. Strain names isolated from farms $\mathrm{B}, \mathrm{C}, \mathrm{D}$, and $\mathrm{O}$ are shown in red, orange, blue, and purple, respectively. Gray boxes indicate the divergence time estimated using BEAST

anti-Sar08 hyperimmune chicken sera with a titer of 5120, which was the same titer obtained with the homologous antigen; H3_ChoB13.5, H3_ChoB13.8, and H3_ChoB14.3 reacted with 32-, 64-, and 64-fold lower titers, respectively. Similar but less extensive changes in reactivity were recognized when antiserum against $\mathrm{H} 3$ _ChoC15.7 was used. The titers of both H3_ChaD12.7 and H3_ChaD13.2 against antiSar08 hyperimmune chicken sera were 16 times lower than the titer of the homologous antigen, whereas H3_ChaD15.7 maintained its titer. Similar results were obtained with antiH3_ChaD15.7 hyperimmune serum. The H3N2 isolates from farms $\mathrm{C}$ and $\mathrm{O}$, both belonging to the human-like $\mathrm{b}$ cluster, showed similar reactivity against the four hyperimmune sera used. In addition, the H3N2 IAV-S isolates from all four farms showed low reactivity to post-infection ferret sera against seasonal human strains from 1995 through 2003 and did not react at all to those from after 2005 (Table 4).

To ascertain whether the antigenic differences observed using hyperimmune chicken and post-infection ferret sera could be detected by naturally infected host animals in the field, we used sera collected from 20-week-old swine at farm C. Specifically, we screened 25 sera obtained from 20 -weekold pigs, which we considered to be unaffected by maternal antibodies, in HI tests. Of these two sera, nos. 1 and 4 , reacted with titers of 160 or more to several H1N1 and $\mathrm{H} 3 \mathrm{~N} 2$ isolates, and both were used for HI tests. For HI tests with the H1N1 strains, two sera, nos. 2 and 3, were added, because they reacted with the two highest titers, except for nos. 1 and 4, to all of the H1N1 strains examined. Sera 5 and 6 were selected for $\mathrm{HI}$ testing with the $\mathrm{H} 3 \mathrm{~N} 2$ strains for the same reason as discussed for the H1 strains. H1_ChoB17.2 showed a 4-fold lower titer than H1_ChoB12.7 to swine sera 2 and 4, suggesting that the antigenic drift observed among $\mathrm{H} 1 \mathrm{~N} 1$ isolates on farm B by using hyperimmune sera could be recognized by serum antibodies in naturally infected pigs. H1_ChoC16.2 reacted similarly to H1_ChoB15.7B with the pig sera. A correlation between antigenicity and phylogenic grouping was evident among the viruses from farm D in regard to sera 1, 3, and 4. H1_ChaD11.2, H1 ChaD11.10, and H1_ChaD12.7, which belonged to 3.3.2b, reacted well with sera 1,3 , and 4 , but those belonging to 3.3.2c-H1_ChaD13.2, H1_ChaD13.8, H1_ChaD13.11, and H1_ChaD14.3-were less reactive. Regarding H3 viruses, H3_ChoB11.2 showed low reactivity to sera 4 and 5 , whereas newer strains showed more than 4-fold higher titers. At farm D, H3_ChaD15.7 showed high reactivity to serum no. 1, whereas older strains were 8 times less reactive.

It is interesting to note that, regardless of the farm sampled, phylogenetically distinct groups showed remarkably different reactivity to swine serum no. 4. Although serum no. 4 did not react with the isolates from farms $\mathrm{C}$ and $\mathrm{O}$ that carried human-like b H3 HA genes, it reacted with the $\mathrm{H} 3 \mathrm{~N} 2$ viruses carrying human-like a H3 HA genes isolated from the other two farms. Considering that serum no. 4 was collected at farm C in July 2015, IAV-S strains that carried human-like b H3 HA genes might have emerged because of the lack of immunity to them on farm C. Isolates from farms $\mathrm{C}$ and $\mathrm{O}$ reacted similarly with sera 1,5 , and 6 . Taken together, our analysis of the Thai isolates indicated that both hyperimmune antisera and naturally infected swine sera revealed antigenic differences not only between phylogenetically distinct groups but also within each group (that is, antigenic drift).

To examine the correlation between antigenic changes and amino acid substitutions in the HA protein, we compared the amino acid substitutions among the H1 (Table S5) and $\mathrm{H} 3$ (Table S6) isolates. Among the H1N1 viruses, several substitutions within predicted antigenic sites deduced by previous studies [46-48] occurred between isolates that showed different antigenicities in the HI tests (Table S5). Among the five amino acid substitutions in the HA protein of H1_ChoB17.2 relative to that of H1_ChoB12.7, two within predicted antigenic sites possibly contributed to the gradual antigenic drift observed in the HI test. Likewise, any of the four substitutions within the predicted antigenic sites between older strains (H1_ChaD11.2, H1_ChaD11.10, and H1_ChaD12.7) and recent strains (H1_ChaD13.2, H1_ ChaD13.8, H1_ChaD13.11, and H1_ChaD14.3) are likely to be related to the different reactivities against swine serum no. 4. Because the H3N2 isolates demonstrated many substitutions even within the antigenic sites deduced in a previous report [49], it was difficult to identify which substitution was associated with an antigenic difference. Compared with H3_ChoB11.2, the H3N2 isolates from farm B after 2013, H3_ChoB13.5, H3_ChoB13.8, and H3_ChoB14.3, which showed different reactivity to hyperimmune sera against Sar08 and swine sera 4 and 5, shared 14 substitutions within the predicted antigenic sites (Table S6). Among the isolates from farm $\mathrm{D}$, five substitutions within the predicted antigenic sites were present between older strains (H3_ChaD12.7 and H3_ChaD13.2) and the most recent (H3_ChaD15.7) that showed different reactivities to antisera against Sar08 and Whu95 and swine serum no. 1 (Table 5). Compared with H3_ChoB11.2 of human-like a, the H3N2 isolates of humanlike b (H3_ChoC15.7, H3_ChoC17.2, H3_ChaO16.7, and H3_ChaO17.7) shared more than 18 substitutions within predicted antigenic sites. 
Table 1 Estimated divergence time of the HA and PB1 genes in each genetic group

\begin{tabular}{llllll}
\hline Gene group & H1 HA & & & PB1 \\
\cline { 2 - 3 } \cline { 6 - 6 } & Branch node & 95\% HPDV & & \\
& 17 Jan 2010 & 20 Oct 2009 - 22 Apr 2010 & & 19 Feb 2010 & 19 Oct 2009 - 19 Jun 2010 \\
3.3.2a & 25 Jul 2009 & 12 Jul 2009 - 25 Jul 2009 & & 29 Mar 2009 & 5 Nov 2008 - 19 Jul 2009 \\
$3.3 .2 \mathrm{~b}$ & 25 Jan 2011 & 18 Oct 2010 - 4 Apr 2011 & & 2 July 2010 & 4 Apr 2010 - 31 August 2010 \\
$3.3 .2 \mathrm{c}$ & & & & &
\end{tabular}

${ }^{\mathrm{a}}$ Highest posterior density value

Table 2 Gene constellations of influenza A viruses of swine isolated in this study

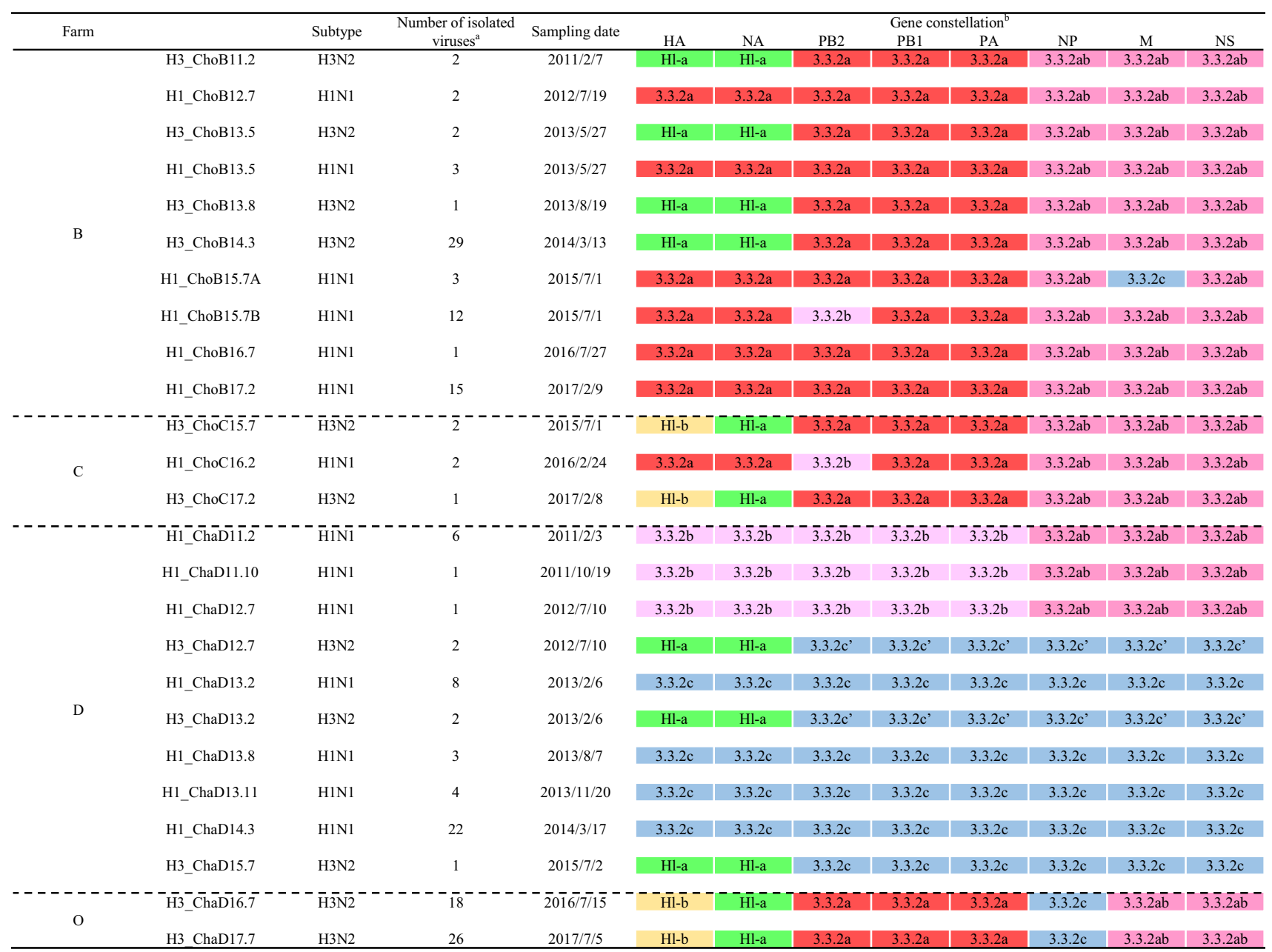

${ }^{a}$ All IAVs-S isolated in this study are listed in Table S4

${ }^{\mathrm{b}}$ Genetic groups are colored as follows: 3.3.2a; red, 3.3.2b; pink, 3.3.2c; blue, 3.3.2ab; bright purple, Hl-a; green, Hl-b; yellow. Differences in nomenclature between this paper and a previous report [29] are as follows: 3.3.2b (this study), Pdm-2 (PB2); 3.3.2c, Pdm-1 (PB1 and NS); 3.3.2b, Pdm-3 (PA); 3.3.2ab, Pdm-2 (NP); 3.3.2c, Pdm-3b (MP). Viruses labeled as "Hl" and "3.3.2" originated from human-like H3N2 IAVs-S and $\mathrm{H} 1 \mathrm{~N} 1 \mathrm{pdm} 09$ viruses, respectively

To assess whether the HA protein of the $\mathrm{H} 1$ isolates from farm B had undergone selection pressure for evading host immune surveillance, we compared the ratio of nonsynonymous to synonymous nucleotide substitution rates $(\mathrm{Ka} /$ Ks ratios) [50] of their HA genes. Because internal genes appear to be less vulnerable to such selection pressure than surface genes, we calculated the $\mathrm{Ka} / \mathrm{Ks}$ ratios of their PB1 genes for comparison (Table 5). The $\mathrm{Ka} / \mathrm{Ks}$ ratios of the $\mathrm{H} 1$ HA genes were significantly higher than those of their PB1 genes ( $t$-test, $P<0.01)$. In addition, the substitution rates within these viruses were significantly higher for the HA genes $\left(4.9 \times 10^{-3}\right.$ substitutions/genome/year; 95\% HPDV, $3.5 \times 10^{-3}$ to $\left.6.3 \times 10^{-3}\right)$ than for the PB1 genes $\left(2.6 \times 10^{-3}\right.$ substitutions/genome/year; $95 \%$ HPDV, $1.8 \times 10^{-3}$ to 
Table 3 Hemagglutination inhibition (HI) titers against the $\mathrm{H} 1$ viruses

\begin{tabular}{|c|c|c|c|c|c|c|c|c|}
\hline \multirow[t]{3}{*}{ Antigen } & \multirow[t]{3}{*}{ Farm } & \multicolumn{7}{|c|}{ HI titer with antisera ${ }^{a}$} \\
\hline & & \multicolumn{3}{|c|}{ Hyperimmune chicken sera } & \multicolumn{4}{|c|}{$\begin{array}{l}\text { Sera from } 20 \text {-week-old swine } \\
\text { at farm } C^{\text {b }}\end{array}$} \\
\hline & & Cal09 & Nar11 & H1_ChoC16.2 & no. 1 & no. 2 & no. 3 & no. 4 \\
\hline Nar09 & & 2560 & 1280 & 640 & 320 & 160 & 320 & 80 \\
\hline Cal09 & & $\underline{2560}$ & 1280 & 640 & 160 & 160 & 640 & 160 \\
\hline Nar11 & & 2560 & $\underline{1280}$ & 320 & 160 & 160 & 640 & 160 \\
\hline H1_ChoB12.7 & B & 2560 & 1280 & 640 & 160 & 320 & 640 & 160 \\
\hline H1_ChoB13.5 & & 1280 & 640 & 640 & 320 & 320 & 320 & 160 \\
\hline H1_ChoB15.7A & & 2560 & 640 & 640 & 160 & 160 & 320 & 80 \\
\hline H1_ChoB15.7B & & 2560 & 640 & 320 & 320 & 160 & 320 & 80 \\
\hline H1_ChoB16.7 & & 2560 & 1280 & 320 & 160 & 160 & 320 & 80 \\
\hline H1_ChoB17.2 & & 1280 & 320 & 160 & 80 & 80 & 160 & 40 \\
\hline H1_ChoC16.2 & $\mathrm{C}$ & 2560 & 640 & $\underline{640}$ & 320 & 160 & 320 & 80 \\
\hline H1_ChaD11.2 & $\mathrm{D}$ & 2560 & 640 & 160 & 160 & 80 & 320 & 80 \\
\hline H1_ChaD11.10 & & 1280 & 640 & 320 & 160 & 160 & 320 & 160 \\
\hline H1_ChaD12.7 & & 2560 & 640 & 160 & 80 & 40 & 160 & 40 \\
\hline H1_ChaD13.2 & & 1280 & 160 & 640 & 20 & 80 & 80 & $<20$ \\
\hline H1_ChaD13.8 & & 1280 & 160 & 640 & 20 & 80 & 80 & 20 \\
\hline H1_ChaD13.11 & & 1280 & 640 & 640 & 40 & 80 & 80 & $<20$ \\
\hline H1_ChaD14.3 & & 1280 & 320 & 160 & 40 & 80 & 40 & $<20$ \\
\hline
\end{tabular}

$\left.3.4 \times 10^{-3} ; P<0.01\right)$. We similarly calculated the $\mathrm{Ka} / \mathrm{Ks}$ ratios and mutation rates of the $\mathrm{H} 3 \mathrm{~N} 2$ viruses from farm $\mathrm{D}$ because they also had evolved as a single lineage with antigenic change (Table 5). The $\mathrm{Ka} / \mathrm{Ks}$ ratios and substitution rates of their $\mathrm{H} 3 \mathrm{HA}$ genes were significantly higher than those of their own PB1 genes $(P=0.03$ and $P<0.01$, respectively). These results suggest that selection pressure, possibly due to immune pressure, in the pig population may have driven the antigenic drift of the HA genes of these viruses within the same farm.

\section{Discussion}

To investigate the evolution of IAV-S within a farm, we conducted a longitudinal study at five pig farms in Thailand, which yielded $169 \mathrm{IAV}-\mathrm{S}$ isolates consisting of H1N1 and $\mathrm{H} 3 \mathrm{~N} 2$ viruses. Our phylogenetic and antigenic analyses demonstrated the dynamics of various IAV-S strains due to accumulation of mutations, multiple introductions of viruses, and reassortment events in the pig farm setting. Through surveillance at these farms, we confirmed the presence of antigenic drift over several years due to the accumulation of amino acid substitutions in the HA protein, and we documented multiple introductions of viruses followed by reassortment events that generated the observed genetic and antigenic diversity. Both events could contribute to the maintenance of IAV-S on a pig farm and to the generation of new viruses.

Regarding the dynamics of a particular subtype of IAV-S on a farm, we observed in this study that IAVs-S with similar antigenicity persisted on a farm for approximately 1 year and then became undetectable, followed by an approximately 1 -year interlude and then resurgence of a virus with the same subtype but different antigenicity. Antigenic alteration at the time of resurgence was caused by either antigenic drift or the introduction of a virus belonging to another sublineage (Tables 2, 3, 4). Sun et al. demonstrated that IAV-S expanded easily and rapidly on a farm, thus raising the herd immunity level against the IAV-S within 100 days after the first infection sufficiently high to prevent virus shedding during a second infection [51]. Given the similar dynamics that occurred within the swine population on farm B, rapid expansion of viruses likewise could have elevated herd antibody titers, thus restricting the prevalence of a circulating virus to below the detection limit. This high immune pressure might have led to the antigenic drift in the H1N1 viruses from farm B such that, for example, H1_ChoB12.7 accumulated substitutions for 3 years and resurged as H1_ChoB15.7A/B, followed by H1_ChoB16.7 and H1_ ChoB17.2. Over 4 years, these viruses gradually became less reactive to naturally infected pig sera, as typically seen 


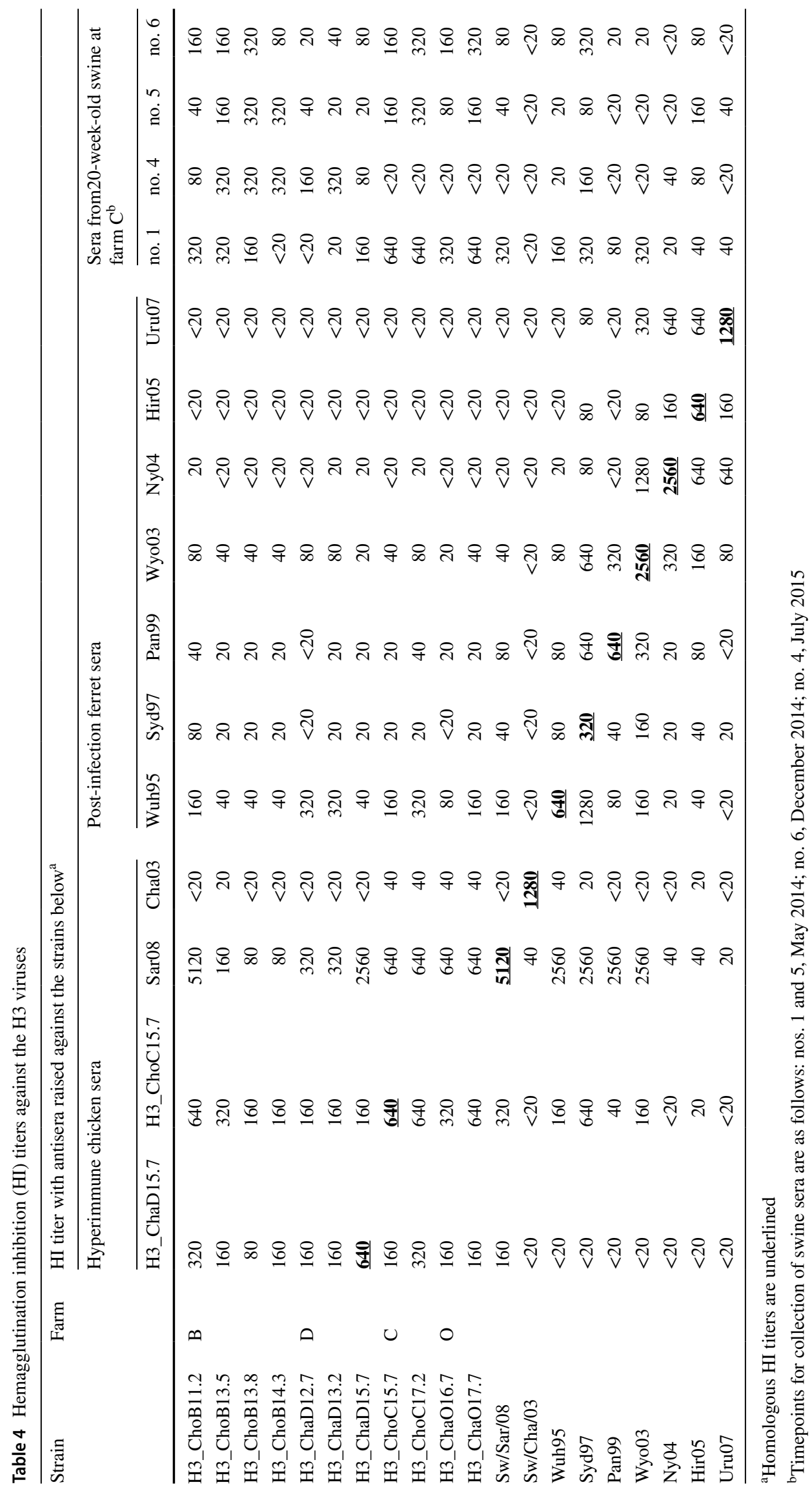


Table $5 \mathrm{Ka} / \mathrm{Ks}$ ratio and substitution rates of $\mathrm{H} 1 \mathrm{~N} 1$ and H3N2 viruses used in this study

\begin{tabular}{|c|c|c|c|c|c|c|c|}
\hline \multirow[t]{2}{*}{ Virus } & \multirow[t]{2}{*}{ Subtype } & \multirow[t]{2}{*}{ Segment } & \multicolumn{2}{|c|}{$\mathrm{Ka} / \mathrm{Ks}^{\mathrm{a}}$} & \multicolumn{3}{|c|}{ Substitution rate } \\
\hline & & & Ratio & $P^{\mathrm{c}}$ & Rate & $95 \% \mathrm{HPDV}^{\mathrm{b}}$ & $P$ \\
\hline $\begin{array}{l}\text { H1_ChoB12.7 } \\
\text { H1_ChoB13.5 } \\
\text { H1_ChoB15.7A } \\
\text { H1_ChoB15.7B } \\
\text { H1_ChoB16.7 } \\
\text { H1_ChoB17.2 }\end{array}$ & $\mathrm{H} 1 \mathrm{~N} 1$ & $\begin{array}{l}\text { HA } \\
\text { PB1 }\end{array}$ & $\begin{array}{l}0.64 \\
0.57\end{array}$ & $<0.01$ & $\begin{array}{l}4.9 \times 10^{-3} \\
2.6 \times 10^{-3}\end{array}$ & $\begin{array}{l}3.5 \times 10^{-3}-6.3 \times 10^{-3} \\
1.8 \times 10^{-3}-3.4 \times 10^{-3}\end{array}$ & $<0.01$ \\
\hline $\begin{array}{l}\text { H3_Cha12.7 } \\
\text { H3_Cha13.2 } \\
\text { H3_ChaD15.7 }\end{array}$ & $\mathrm{H} 3 \mathrm{~N} 2$ & $\begin{array}{l}\mathrm{HA} \\
\mathrm{PB} 1\end{array}$ & $\begin{array}{l}0.72 \\
0.65\end{array}$ & 0.03 & $\begin{array}{l}5.5 \times 10^{-3} \\
3.2 \times 10^{-3}\end{array}$ & $\begin{array}{l}3.5 \times 10^{-3}-7.7 \times 10^{-3} \\
1.7 \times 10^{-3}-4.6 \times 10^{-3}\end{array}$ & $<0.01$ \\
\hline
\end{tabular}

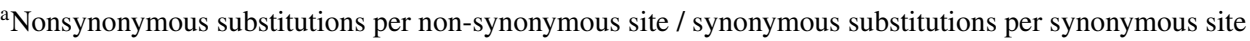

${ }^{\mathrm{b}}$ Highest posterior density value

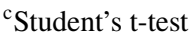

with serum no. 4, suggesting that IAV-S evolves to evade immune pressure in a farm setting. It is unclear whether such antigenic drift under immune pressure actually occurred at the farm level in this study, although previous reports have demonstrated using experimentally infected animals that antigenic drift can occur under immune pressure in a pig $[52,53]$. Other researchers have demonstrated that selection pressure is more intense on the HA1 gene than on internal genes and have hypothesized that IAVs behave as though they are trying to outrun their immune pursuers [54]. Rambaut et al. demonstrated that the antigenic drift of human IAVs due to such selection pressure is a global event, and thus new variants are spread [55]. In the current study, we learned that, in a farm setting, non-synonymous substitutions with higher substitution rates in the HA gene than in the PB1 gene resulted in the emergence of a drifted virus that differed from the strain that had circulated previously in the pig population. However, it remains to be determined whether the drift was a consequence of escape from herd immunity against the strain that had previously been circulating on the farm.

In addition, introductions of viruses of the same subtype but with different antigenicity were another key for evading immune pressure, as seen in the $\mathrm{H} 3 \mathrm{~N} 2$ viruses on farm $\mathrm{B}$ and H1N1 viruses on farm D. Through a 1-year longitudinal study of farrow-to-wean farms, Diaz et al. documented multiple introductions of H1N1, H1N2, and H3N2 IAV-S on individual farms, with some IAV-S strains retained and others replaced by phylogenetically distinct groups on individual farms [17]. Our current 5-year longitudinal study demonstrated that such introduced viruses can establish themselves on a farm only when the new IAV-S differs in antigenicity from the pre-existing IAV-S strains on that farm.

The isolation from four Thai pig farms of $\mathrm{A}(\mathrm{H} 1 \mathrm{~N} 1)$ pdm09 viruses and of H3N2 viruses whose internal genes were replaced by those of $\mathrm{A}(\mathrm{H} 1 \mathrm{~N} 1) \mathrm{pdm} 09$ viruses demonstrates interspecies transmission from humans to swine and subsequent reassortment in pigs, as reported previously [30, $33,56,57]$. The three epidemic peaks of $\mathrm{A}(\mathrm{H} 1 \mathrm{~N} 1) \mathrm{pdm} 09$ virus in the human population in Thailand-August 2009, February 2010, and September 2010-were followed by another peak in 2014, and few cases of A(H1N1)pdm09 infection in humans were recorded between 2011 and 2013 $[58,59]$. Our genetic analysis of IAV-S isolates of A(H1N1) pdm09 origin revealed a close genetic relationship between the IAV-S strains from the pig farms and human epidemic strains (Fig. 1a-c). 3.3.2a and 3.3.2b of H1 HA genes were estimated to diverge in October 2009 and July 2009, respectively, suggesting that they were introduced into pig farms around the first epidemic peak in the human population in Thailand. Likewise, 3.3.2c of H1 HA genes was estimated to diverge in September 2010, coinciding with the third epidemic peak in the human population. This finding suggests that the magnitude of an epidemic in the human population might promote interspecies transmission of IAVs to the pig population. Studying the timing of influenza outbreaks in human and pig populations is important for revealing the mechanisms underlying the introduction of a human epidemic influenza virus into pig farms.

During our active surveillance, we detected IAV-S on multiple occasions on farms B, C, D, and O, whereas we detected no IAV-S during any of the four sampling events on farm P. A previous report showed that farms with more than 1000 pigs are at increased risk for IAV-S positivity [60]. In that regard, each of the five farms in our study had more than 1000 pigs, thus ruling out the possibility that the different isolation rates were due to differences in the number of pigs on the surveyed farms. In addition, the farms we tested maintained similar animal husbandry practices, mandating workers to wear dedicated clothes and boots and to shower before and after handling pigs (Table S1). The only husbandry practice that differed between farm $\mathrm{P}$ and the other four farms that might have resulted in their differing hygiene status was that workers on farm $\mathrm{P}$ wore masks when 
handling pigs. Wearing masks might reduce the pigs' exposure to aerosolized infectious influenza virus from humans, thus decreasing the risk of transmission of human seasonal influenza virus on the farm. However, the small sample size precludes the demonstration of a significant correlation between the presence of IAV-S and the wearing of masks by workers. Further investigation of the ability of masks to prevent human-to-pig transmission is needed.

In summary, we used continuous longitudinal surveillance to show how IAV-S generated genetic and antigenic diversity over several years in a pig farm setting; antigenic drift due to the accumulation of substitutions in antigenic sites in the HA gene contributed to the evolution of IAVs-S. In addition, the introduction of viruses with different antigenicity was confirmed. At the farm level, both of these events appeared to be important for the evasion of host immunity and subsequent circulation and resurgence of IAV-S. One remarkable feature of our study is that it indicates that both multiple introductions of IAV-S and accumulation of substitutions in the HA proteins had occurred, resulting in the antigenic evolution and long-term circulation of IAV-S within a farm. Although we found evidence of multiple introductions into and resurgence of viruses on the pig farms we monitored, additional clues regarding how such introductions occurred would help to prevent similar introductions and to control IAV infections in pigs.

Acknowledgements All antisera raised against human $\mathrm{H} 3 \mathrm{~N} 2$ viruses, the homologous inactivated antigens, and A/Narita/1/2009 were kindly provided by the National Institute of Infectious Diseases, Japan; A/California/04/2009 was kindly provided by the Centers for Disease Control and Prevention, USA. We thank the staff of the National Institute of Animal Health, Thailand, for arranging and supporting our collection of pig swab samples in Thailand. All of the analyses involving the BEAST software package were conducted by using the supercomputer of AFFRIT, MAFF, Japan. The current research was supported by the Japan Initiative for Global Research Network on Infectious Diseases (J-GRID) from the Ministry of Education, Culture, Sports, Science, and Technology in Japan and by the Japan Agency for Medical Research and Development (AMED) under grant number JP18fm0108008.

\section{Compliance with ethical standards}

Conflict of interest The authors declare that they have no competing interests.

Ethics statement This article does not contain any studies involving human participants or live animals that were performed by any of the authors.

\section{References}

1. Bennett R, Ijpelaar J (2005) Updated estimates of the costs associated with thirty-four endemic livestock diseases in Great Britain: a note. J Agric Econ 56:135-144. https://doi. org/10.1111/j.1477-9552.2005.tb00126.x
2. FAO (2009) The human influenza due to a novel subtype H1N1. http://www.fao.org/3/a-ak061e.pdf. Accessed 26 Jan 2016

3. Kitikoon P, Vincent AL, Jones KR, Nilubol D, Yu S, Janke BH, Thacker BJ, Thacker EL (2009) Vaccine efficacy and immune response to swine influenza virus challenge in pigs infected with porcine reproductive and respiratory syndrome virus at the time of SIV vaccination. Vet Microbiol 139:235-244. https://doi. org/10.1016/j.vetmic.2009.06.003

4. Brown IH (2000) The epidemiology and evolution of influenza viruses in pigs. Vet Microbiol 74:29-46. https://doi.org/10.1016/ S0378-1135(00)00164-4

5. Vincent A, Awada L, Brown I, Chen H, Claes F, Dauphin G, Donis R, Culhane M, Hamilton K, Lewis N, Mumford E, Nguyen T, Parchariyanon S, Pasick J, Pavade G, Pereda A, Peiris M, Saito T, Swenson S, Van Reeth K, Webby R, Wong F, Ciacci-Zanella J (2014) Review of influenza A virus in swine worldwide: a call for increased surveillance and research. Zoonoses Public Health 61:4-17. https://doi.org/10.1111/zph.12049

6. Zhu H, Webby R, Lam TT, Smith DK, Peiris JS, Guan Y (2013) History of Swine influenza viruses in Asia. Curr Top Microbiol Immunol 370:57-68. https://doi.org/10.1007/82_2011_179

7. Zell R, Scholtissek C, Ludwig S (2013) Genetics, evolution, and the zoonotic capacity of European Swine influenza viruses. Curr Top Microbiol Immunol 370:29-55. https://doi. org/10.1007/82_2012_267

8. Zhou NN, Senne DA, Landgraf JS, Swenson SL, Erickson G, Rossow K, Liu L, Yoon K, Krauss S, Webster RG (1999) Genetic reassortment of avian, swine, and human influenza A viruses in American pigs. J Virol 73:8851-8856

9. Garten RJ, Davis CT, Russell CA, Shu B, Lindstrom S, Balish A, Sessions WM, Xu X, Skepner E, Deyde V, Okomo-Adhiambo M, Gubareva L, Barnes J, Smith CB, Emery SL, Hillman MJ, Rivailler P, Smagala J, de Graaf M, Burke DF, Fouchier RA, Pappas C, Alpuche-Aranda CM, Lopez-Gatell H, Olivera H, Lopez I, Myers CA, Faix D, Blair PJ, Yu C, Keene KM, Dotson PD Jr, Boxrud D, Sambol AR, Abid SH, St George K, Bannerman T, Moore AL, Stringer DJ, Blevins P, Demmler-Harrison GJ, Ginsberg M, Kriner P, Waterman S, Smole S, Guevara HF, Belongia EA, Clark PA, Beatrice ST, Donis R, Katz J, Finelli L, Bridges CB, Shaw M, Jernigan DB, Uyeki TM, Smith DJ, Klimov AI, Cox NJ (2009) Antigenic and genetic characteristics of swine-origin 2009 A(H1N1) influenza viruses circulating in humans. Science 325:197-201. https://doi.org/10.1126/science.1176225

10. Smith GJ, Vijaykrishna D, Bahl J, Lycett SJ, Worobey M, Pybus OG, Ma SK, Cheung CL, Raghwani J, Bhatt S, Peiris JS, Guan Y, Rambaut A (2009) Origins and evolutionary genomics of the 2009 swine-origin H1N1 influenza A epidemic. Nature 459:1122-1125. https://doi.org/10.1038/nature08182

11. Sreta D, Tantawet S, Na Ayudhya SN, Thontiravong A, Wongphatcharachai M, Lapkuntod J, Bunpapong N, Tuanudom R, Suradhat S, Vimolket L, Poovorawan Y, Thanawongnuwech R, Amonsin A, Kitikoon P (2010) Pandemic (H1N1) 2009 virus on commercial swine farm, Thailand. Emerg Infect Dis 16:15871590. https://doi.org/10.3201/eid1610.100665

12. Vijaykrishna D, Poon LL, Zhu HC, Ma SK, Li OT, Cheung CL, Smith GJ, Peiris JS, Guan Y (2010) Reassortment of pandemic H1N1/2009 influenza A virus in swine. Science 328:1529. https ://doi.org/10.1126/science.1189132

13. Howard WA, Essen SC, Strugnell BW, Russell C, Barass L, Reid SM, Brown IH (2011) Reassortant Pandemic (H1N1) 2009 virus in pigs, United Kingdom. Emerg Infect Dis 17:1049-1052. https ://doi.org/10.3201/eid/1706.101886

14. Kitikoon P, Sreta D, Na Ayudhya SN, Wongphatcharachai M, Lapkuntod J, Prakairungnamthip D, Bunpapong N, Suradhat S, Thanawongnuwech R, Amonsin A (2011) Brief report: Molecular characterization of a novel reassorted pandemic H1N1 2009 
in Thai pigs. Virus Genes 43:1-5. https://doi.org/10.1007/s1126 2-011-0597-5

15. Lam TT, Zhu H, Wang J, Smith DK, Holmes EC, Webster RG, Webby R, Peiris JM, Guan Y (2011) Reassortment events among swine influenza A viruses in China: implications for the origin of the 2009 influenza pandemic. J Virol 85:10279-10285. https://doi.org/10.1128/JVI.05262-11

16. Moreno A, Di Trani L, Faccini S, Vaccari G, Nigrelli D, Boniotti MB, Falcone E, Boni A, Chiapponi C, Sozzi E, Cordioli P (2011) Novel H1N2 swine influenza reassortant strain in pigs derived from the pandemic H1N1/2009 virus. Vet Microbiol 149:472-477. https://doi.org/10.1016/j.vetmic.2010.12.011

17. Diaz A, Marthaler D, Culhane M, Sreevatsan S, Alkhamis M, Torremorell M (2017) Complete genome sequencing of influenza A viruses within swine farrow-to-wean farms reveals the emergence, persistence, and subsidence of diverse viral genotypes. J Virol. https://doi.org/10.1128/JVI.00745-17

18. Takemae N, Parchariyanon S, Ruttanapumma R, Hiromoto Y, Hayashi T, Uchida Y, Saito T (2011) Swine influenza virus infection in different age groups of pigs in farrow-to-finish farms in Thailand. Virol J 8:537. https://doi. org/10.1186/1743-422X-8-537

19. Yassine HM, Lee CW, Saif YM (2013) Interspecies transmission of influenza a viruses between Swine and poultry. Curr Top Microbiol Immunol 370:227-240. https://doi.org/10.1007/82_2011_180

20. Bonfante F, Fusaro A, Tassoni L, Patrono LV, Milani A, Maniero S, Salviato A, Terregino C (2016) Spillback transmission of European H1N1 avian-like swine influenza viruses to turkeys: a strain-dependent possibility? Vet Microbiol 186:102-110. https ://doi.org/10.1016/j.vetmic.2016.02.025

21. Nelson MI, Viboud C, Vincent AL, Culhane MR, Detmer SE, Wentworth DE, Rambaut A, Suchard MA, Holmes EC, Lemey $P$ (2015) Global migration of influenza A viruses in swine. Nat Commun 6:6696. https://doi.org/10.1038/ncomms7696

22. Rejmanek D, Hosseini PR, Mazet JA, Daszak P, Goldstein T (2015) Evolutionary dynamics and global diversity of influenza A virus. J Virol 89:10993-11001. https://doi.org/10.1128/JVI.01573 $-15$

23. FAO (2015): FAOSTAT data. http://faostat.fao.org/. Accessed 27 Jan 2016

24. Nerome K, Ishida M, Nakayama M, Oya A, Kanai C, Suwicha K (1981) Antigenic and genetic analysis of A/Hong Kong (H3N2) influenza viruses isolated from swine and man. J Gen Virol 56:441-445. https://doi.org/10.1099/0022-1317-56-2-441

25. Nerome K, Ishida M, Oya A, Kanai C, Suwicha K (1982) Isolation of an influenza H1N1 virus from a pig. Virology 117:485-489. https://doi.org/10.1016/0042-6822(82)90486-X

26. Chutinimitkul S, Thippamom N, Damrongwatanapokin S, Payungporn S, Thanawongnuwech R, Amonsin A, Boonsuk P, Sreta D, Bunpong N, Tantilertcharoen R, Chamnanpood P, Parchariyanon S, Theamboonlers A, Poovorawan Y (2008) Genetic characterization of $\mathrm{H} 1 \mathrm{~N} 1, \mathrm{H} 1 \mathrm{~N} 2$ and $\mathrm{H} 3 \mathrm{~N} 2$ swine influenza virus in Thailand. Arch Virol 153:1049-1056. https://doi.org/10.1007/ s00705-008-0097-7

27. Takemae N, Parchariyanon S, Damrongwatanapokin S, Uchida Y, Ruttanapumma R, Watanabe C, Yamaguchi S, Saito T (2008) Genetic diversity of swine influenza viruses isolated from pigs during 2000 to 2005 in Thailand. Influ Other Respir Viruses 2:181-189. https://doi.org/10.1111/j.1750-2659.2008.00062.x

28. Poonsuk S, Sangthong P, Petcharat N, Lekcharoensuk P (2013) Genesis and genetic constellations of swine influenza viruses in Thailand. Vet Microbiol 167:314-326. https://doi.org/10.1016/j. vetmic.2013.09.007

29. Nonthabenjawan N, Chanvatik S, Chaiyawong S, Jairak W, Boonyapisusopha S, Tuanudom R, Thontiravong A, Bunpapong N, Amonsin A (2015) Genetic diversity of swine influenza viruses in Thai swine farms, 2011-2014. Virus Genes 50:221-230. https ://doi.org/10.1007/s11262-014-1153-x

30. Hiromoto Y, Parchariyanon S, Ketusing N, Netrabukkana P, Hayashi T, Kobayashi T, Takemae N, Saito T (2012) Isolation of the pandemic (H1N1) 2009 virus and its reassortant with an H3N2 swine influenza virus from healthy weaning pigs in Thailand in 2011. Virus Res 169:175-181. https://doi.org/10.1016/j. virusres.2012.07.025

31. Charoenvisal N, Keawcharoen J, Sreta D, Chaiyawong S, Nonthabenjawan N, Tantawet S, Jittimanee S, Arunorat J, Amonsin A, Thanawongnuwech R (2013) Genetic characterization of Thai swine influenza viruses after the introduction of pandemic H1N1 2009. Virus Genes 47:75-85. https://doi.org/10.1007/s 1126 2-013-0927-x

32. Arunorat J, Charoenvisal N, Woonwong Y, Kedkovid R, Thanawongnuwech R (2016) Determination of current reference viruses for serological study of swine influenza viruses after the introduction of pandemic 2009 H1N1 (pdmH1N1) in Thailand. J Virol Methods 236:5-9. https://doi.org/10.1016/j.jviromet.2016.06.010

33. Abe H, Mine J, Parchariyanon S, Takemae N, Boonpornprasert P, Ubonyaem N, Patcharasinghawut P, Nuansrichay B, Tanikawa T, Tsunekuni R, Saito T (2015) Co-infection of influenza A viruses of swine contributes to effective shuffling of gene segments in a naturally reared pig. Virology 484:203-212. https:// doi.org/10.1016/j.virol.2015.06.002

34. Simon-Grife M, Martin-Valls GE, Vilar MJ, Busquets N, MoraSalvatierra M, Bestebroer TM, Fouchier RA, Martin M, Mateu E, Casal J (2012) Swine influenza virus infection dynamics in two pig farms; results of a longitudinal assessment. Vet Res 43:24. https://doi.org/10.1186/1297-9716-43-24

35. Rose N, Herve S, Eveno E, Barbier N, Eono F, Dorenlor V, Andraud M, Camsusou C, Madec F, Simon G (2013) Dynamics of influenza A virus infections in permanently infected pig farms: evidence of recurrent infections, circulation of several swine influenza viruses and reassortment events. Vet Res 44:72. https://doi. org/10.1186/1297-9716-44-72

36. Thrusfield M (1995) Veterinary epidemiology, vol 2. Blackwell Science Ltd., Oxford

37. Huddleston JA, Brownlee GG (1982) The sequence of the nucleoprotein gene of human influenza A virus, strain A/NT/60/68. Nucleic Acids Res 10:1029-1038

38. Ngo LT, Hiromoto Y, Pham VP, Le HT, Nguyen HT, Le VT, Takemae N, Saito T (2012) Isolation of novel triple-reassortant swine H3N2 influenza viruses possessing the hemagglutinin and neuraminidase genes of a seasonal influenza virus in Vietnam in 2010. Influ Other Respir Viruses 6:6-10. https://doi.org/10.111 $1 / \mathrm{j} .1750-2659.2011 .00267 . \mathrm{x}$

39. WHO (2002) The human influenza due to a novel subtype H1N1. http://www.who.int/csr/resources/publications/influenza/whocd scsrncs20025rev.pdf. Accessed 10 Mar 2016

40. Hall TA (1999) BioEdit: a user-friendly biological sequence alignment editor and analysis program for Windows 95/98/NT. Nucl Acids Symp Ser 41:95-98

41. Katoh K, Standley DM (2016) A simple method to control overalignment in the MAFFT multiple sequence alignment program. Bioinformatics 32:1933-1942. https://doi.org/10.1093/bioinforma tics/btw108

42. Kumar S, Stecher G, Peterson D, Tamura K (2012) MEGA-CC: computing core of molecular evolutionary genetics analysis program for automated and iterative data analysis. Bioinformatics 28:2685-2686. https://doi.org/10.1093/bioinformatics/bts507

43. Drummond AJ, Suchard MA, Xie D, Rambaut A (2012) Bayesian phylogenetics with BEAUti and the BEAST 1.7. Mol Biol Evol 29:1969-1973. https://doi.org/10.1093/molbev/mss075

44. Bouckaert R, Heled J, Kuhnert D, Vaughan T, Wu CH, Xie D, Suchard MA, Rambaut A, Drummond AJ (2014) BEAST 2: a 
software platform for Bayesian evolutionary analysis. PLoS Comput Biol 10:e1003537. https://doi.org/10.1371/journal.pcbi.10035 37

45. Anderson TK, Macken CA, Lewis NS, Scheuermann RH, Van Reeth K, Brown IH, Swenson SL, Simon G, Saito T, Berhane Y, Ciacci-Zanella J, Pereda A, Davis CT, Donis RO, Webby RJ, Vincent AL (2016) A phylogeny-based global nomenclature system and automated annotation tool for $\mathrm{H} 1$ hemagglutinin genes from swine influenza A viruses. mSphere. https://doi.org/10.1128/ mSphere.00275-16

46. Caton AJ, Brownlee GG, Yewdell JW, Gerhard W (1982) The antigenic structure of the influenza virus $\mathrm{A} / \mathrm{PR} / 8 / 34$ hemagglutinin (H1 subtype). Cell 31:417-427. https://doi.org/10.1016/00928674(82)90135-0

47. Igarashi M, Ito K, Yoshida R, Tomabechi D, Kida H, Takada A (2010) Predicting the antigenic structure of the pandemic (H1N1) 2009 influenza virus hemagglutinin. PLoS One 5:e8553. https:// doi.org/10.1371/journal.pone.0008553

48. Matsuzaki Y, Sugawara K, Nakauchi M, Takahashi Y, Onodera T, Tsunetsugu-Yokota Y, Matsumura T, Ato M, Kobayashi K, Shimotai Y, Mizuta K, Hongo S, Tashiro M, Nobusawa E (2014) Epitope mapping of the hemagglutinin molecule of $\mathrm{A} /(\mathrm{H} 1 \mathrm{~N} 1)$ pdm09 influenza virus by using monoclonal antibody escape mutants. J Virol 88:12364-12373. https://doi.org/10.1128/JVI.01381-14

49. Wiley DC, Wilson IA, Skehel JJ (1981) Structural identification of the antibody-binding sites of Hong Kong influenza haemagglutinin and their involvement in antigenic variation. Nature 289:373-378. https://doi.org/10.1038/289373a0

50. Kryazhimskiy S, Plotkin JB (2008) The population genetics of dN/dS. PLoS Genet 4:e1000304. https://doi.org/10.1371/journ al.pgen.1000304

51. Sun H, Cunningham FL, Harris J, Xu Y, Long LP, Hanson-Dorr K, Baroch JA, Fioranelli P, Lutman MW, Li T, Pedersen K, Schmit BS, Cooley J, Lin X, Jarman RG, DeLiberto TJ, Wan XF (2015) Dynamics of virus shedding and antibody responses in influenza A virus-infected feral swine. J Gen Virol 96:2569-2578. https:// doi.org/10.1099/jgv.0.000225

52. Murcia PR, Hughes J, Battista P, Lloyd L, Baillie GJ, RamirezGonzalez RH, Ormond D, Oliver K, Elton D, Mumford JA, Caccamo M, Kellam P, Grenfell BT, Holmes EC, Wood JL (2012)
Evolution of an Eurasian avian-like influenza virus in naive and vaccinated pigs. PLoS Pathog 8:e1002730. https://doi. org/10.1371/journal.ppat.1002730

53. Diaz A, Allerson M, Culhane M, Sreevatsan S, Torremorell M (2013) Antigenic drift of H1N1 influenza A virus in pigs with and without passive immunity. Influ Other Respir Viruses 7(Suppl 4):52-60. https://doi.org/10.1111/irv. 12190

54. Fitch WM, Leiter JM, Li XQ, Palese P (1991) Positive Darwinian evolution in human influenza A viruses. Proc Natl Acad Sci USA 88:4270-4274. https://doi.org/10.1073/pnas.88.10.4270

55. Rambaut A, Pybus OG, Nelson MI, Viboud C, Taubenberger JK, Holmes EC (2008) The genomic and epidemiological dynamics of human influenza A virus. Nature 453:615-619. https://doi. org/10.1038/nature06945

56. Nelson MI, Stratton J, Killian ML, Janas-Martindale A, Vincent AL (2015) Continual reintroduction of human pandemic H1N1 influenza A viruses into swine in the United States, 2009 to 2014. J Virol 89:6218-6226. https://doi.org/10.1128/JVI.00459-15

57. Tinoco YO, Montgomery JM, Kasper MR, Nelson MI, Razuri $\mathrm{H}$, Guezala MC, Azziz-Baumgartner E, Widdowson MA, Barnes J, Gilman RH, Bausch DG, Gonzalez AE (2016) Transmission dynamics of pandemic influenza A(H1N1)pdm09 virus in humans and swine in backyard farms in Tumbes, Peru. Influ Other Respir Viruses 10:47-56. https://doi.org/10.1111/irv.12329

58. Prachayangprecha S, Makkoch J, Vuthitanachot C, Vuthitanachot V, Payungporn S, Chieochansin T, Theamboonlers A, Poovorawan Y (2011) Epidemiological and serological surveillance of human pandemic influenza A virus infections during 2009-2010 in Thailand. Jpn J Infect Dis 64:377-381

59. Prachayangprecha S, Vichaiwattana P, Korkong S, Felber JA, Poovorawan Y (2015) Influenza activity in Thailand and occurrence in different climates. SpringerPlus 4:356. https://doi.org/10.1186/ s40064-015-1149-6

60. Takemae N, Shobugawa Y, Nguyen PT, Nguyen T, Nguyen TN, To TL, Thai PD, Nguyen TD, Nguyen DT, Nguyen DK, Do HT, Le TQ, Hua PT, Van Vo H, Nguyen DT, Nguyen DH, Uchida Y, Saito R, Saito T (2016) Effect of herd size on subclinical infection of swine in Vietnam with influenza A viruses. BMC Vet Res 12:227. https://doi.org/10.1186/s12917-016-0844-Z 